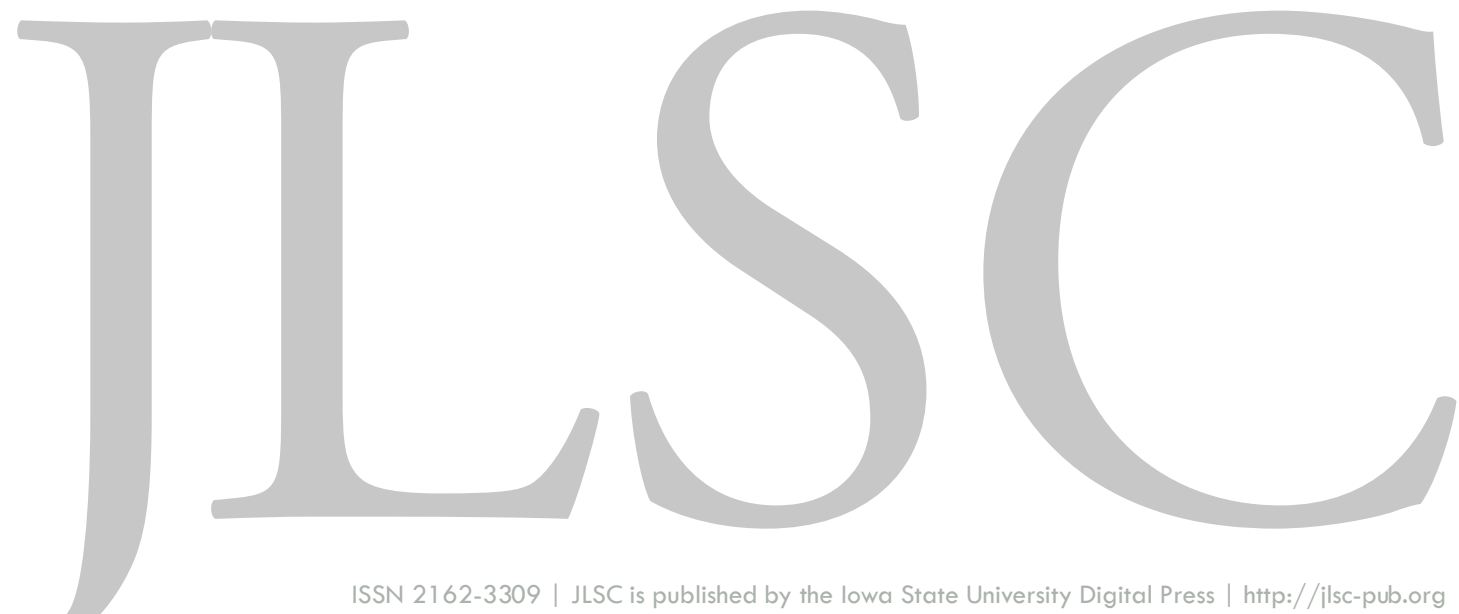

Volume 10, General Issue (2022)

\title{
Library Publishing Programs at Capacity: Addressing Issues of Sustainability and Scalability
}

Johanna Meetz \& Jason Boczar

Meetz, J., \& Boczar, J. (2022). Library Publishing Programs at Capacity: Addressing Issues of Sustainability and Scalability. Journal of Librarianship and Scholarly Communication, 10(1), eP1 2909. https://doi.org/ 10.31274 /ilsc. 12909

This article underwent semi-anonymous peer review in accordance with JLSC's peer review policy. 


\title{
PRACTICE ARTICLE
}

\section{Library Publishing Programs at Capacity: Addressing Issues of Sustainability and Scalability}

\author{
Johanna Meetz \\ The Ohio State University formerly Pacific University \\ Jason Boczar \\ The University of South Florida
}

\section{ABSTRACT}

Introduction: This article discusses the changes to overall goals, direction, and services that were made to two library publishing programs at Pacific University and the University of South Florida when they were no longer able to grow their programs due to an inability to hire additional staff and COVID-19-instigated staff reassignments.

Description of Programs: Pacific University's publishing program grew out of its institutional repository and, at its peak, published seven open access journals. In addition, Pacific University Libraries founded a University Press in 2016, which has published six books as of 2021. The University of South Florida's publishing program began publishing open access journals in 2008, and it has grown to include over 20 journals.

Lessons Learned: Both the Pacific University and the University of South Florida publishing programs have faced scalability and sustainability issues, which were further exacerbated by COVID-19. The focus of our library publishing programs, as well as many others, has been on continual growth, which is not sustainable without the ability to hire additional staff or allocate staff time differently. We argue that standardizing services as well as creating a business plan can help ensure that publishing programs are sustainable and scalable.

Next Steps: We hope to begin a conversation among library publishers about acknowledging limits and creating achievable definitions of success outside of continual growth. 


\section{INTRODUCTION}

In this article, we will discuss two library publishing programs: Pacific University, a small liberal arts institution with about 4,000 students, and the University of South Florida (USF), a large research institution with about 50,000 students. We will detail the history of the growth of both publishing programs. Then, we will describe what happened when Pacific University's program reached capacity and changed focus, and how COVID-19 shined a spotlight on the struggles of sustainability and scalability when it necessitated the redistribution of staff who worked on the University of South Florida's publications, which caused a shift in their service model. We will also offer some strategies to help ensure the sustainability of library publishing programs in the long-term. We hope to start a conversation in the library publishing community around the reality that all publishing programs must face: they cannot expand indefinitely without additional staff time (whether that takes the form of redistributing current staff or hiring additional part time, full time, or freelancers) or changing and/or reducing the services they offer in some way.

\section{LITERATURE REVIEW}

Library publishing is defined by the Library Publishing Coalition as "the set of activities led by college and university libraries to support the creation, dissemination, and curation of scholarly, creative, and/or educational works" (Hawkins et al., 2014). This work generally "requires a production process, presents original work not previously made available, and applies a level of certification to the content published, whether through peer review or extension of the institutional brand" (Hawkins et al., 2014). It is also useful to think of library publishing in terms of its goals rather than the products it produces. For instance, library publishers "generally aspire to provide an alternative publishing model for authors and editors that favors OA ["open access"] and less restrictive licensing" (p. 187; Lippincott, 2016). They also work to "preserve and disseminate the scholarly output of their campus communities and fill gaps in the current scholarly publishing system by providing publishing or simple hosting services" for different types of publications that may not find a home with traditional publishers (p. 187; Lippincott, 2016).

In general, library publishing is "distinguished from other publishing fields by a preference for open access dissemination and a willingness to embrace informal and experimental forms of scholarly communication and to challenge the status quo" (Hawkins et al., 2014). Furthermore, the services library publishers offer complement those offered by traditional scholarly publishers such as commercial publishers and university presses by offering "new, open, and sustainable models for publishing academic research" (p. 187; Lippincott, 2016). In short, library publishing programs produce a wide variety of content by offering varying service levels. This content may be experimental and/or produced in an innovative way, but it always prioritizes openness. The work of library publishers complements and challenges traditional 
publishers while offering opportunities for scholars to disseminate work that may not find a home with a traditional publisher.

Library publishing began as a "natural outgrowth of and corollary to libraries' investment in scholarly communication, digital scholarship, and data management services, among others," and its "emergence...can be directly correlated with perceived failures of and inequities in the contemporary scholarly publishing ecosystem” (p. 6; Lippincott, 2017). Moreover, libraries have a history of publishing, usually "things arising from their own collections and activities, for the benefit of users and potential users of their collections" (p. 2; Okerson and Holzman, 2015). More recently, "library publishing has gained a critical mass within academic libraries and has garnered increasing attention from librarians and publishers alike" (p. 7; Lippincott, 2017). Although it is common for library publishing programs to be created by the already existing institutional repository platform and staff, "in order to scale up, library publishers need to build both capacity and demand," which "may require new staffing lines or reallocated staff time or additional funding to hire vendors and freelancers to do work that cannot be completed in house" (Lippincott, 2016 and p. 41; Lippincott, 2017).

Since the Library Publishing Coalition was founded, it has produced an annual directory of library publishers that details their individual programs (Library Publishing Coalition, 2021b). In 2014, a total of 23 institutions reported publishing journals that were either campus-based and faculty-created, campus-based and student-created, or contracted by external groups (Library Publishing Coalition, 2021b). In 2020, a total of 43 institutions reported publishing in these areas (Library Publishing Coalition, 2021b). Clearly, there has been substantial growth in the area of journal publishing by library publishers. As more libraries have started publishing, individual libraries have also worked to expand their publishing programs. As a result, the library publishing community has discussed how to balance publishing additional journals or expanding the number of services offered with the themes of sustainability, scalability, staffing challenges, project management, and general tips on how to do more with less at the Library Publishing Forum and in scholarly articles. ${ }^{1}$ In fact, growing a publishing

\footnotetext{
${ }^{1}$ See such Library Publishing Program presentations as the following: Staffing a Library Publishing Program: The Whos, Hows, and Whens (2015), Scaling Up OER Publishing with a Networked Approach (2016), Supporting OA Journal Success with Self-Service Solutions and Journal Publication at Columbia University Libraries: A Look at the Development of a New Skill Set (2017), Understanding the New Publishing Goals of Scholars: Tow ard a Sustainable Model for Broadly Accessible Library Publishing (2018), Coalition Publi.ca: A Canadian Initiative for a Sustainable Publishing Environment in HSS (2018), Balancing Vendor Collaborations for Sustainable Library Publishing (2018), On Adding Platforms to Improve Sustainability: The Case for the Minimal Journal, Findable, Impactful, Citable, Usable, Sustainable: A Rubric for Rigorous Digital Publishing (2019), Building a Foundation for Sustainable Library Publishing: Quantitative Tools \& Practical Methods (2020), Creative Staffing Solutions for Library Publishing: Layout, Graphic Design, Copyediting, Project Management, and More (2020), and The Power of No: Building a Sustainable Publishing Program (2021).
} 
program necessitates finding solutions to those problems. However, there has been little to no conversation about what happens when publishing programs have reached capacity, resulting in forced or chosen reductions in projects or services.

\section{DESCRIPTION OF PROGRAMS}

\section{Pacific University}

Journal publishing at Pacific University began in 2009 as an extension of its successful institutional repository program, and, at its peak, the publishing program published seven open access journals. Pacific offers a more full-service model than is typical of most library publishers that includes copyediting and typesetting. In 2015, the Libraries expanded its publishing program by creating Pacific University Press, which is library-born and publishes open access digital books in addition to selling print copies. The Press works to create "opportunities for authors with diverse viewpoints to share their scholarly and creative work" as well as to promote "the discovery and use of that work through the use of open access and hybrid publishing and agile licensing models" (Pacific University Press, 2021). Since it was created, six Pacific University Press books have been published, and eight other books have also been published via Bee Tree Books, an imprint that was created alongside Pacific University Press to publish books more informally that have a connect to Pacific University.

Despite the exponential growth of the publishing program between 2009 and 2019, other responsibilities of the scholarly communication and publishing services librarian were not reduced to accommodate the increased production work, and no additional faculty or staff were hired. This meant that, in addition to overseeing and completing the work of the publishing program, the scholarly communication and publishing services librarian remained in charge of administering the institutional repository and all of its associated tasks. By 2018, it became evident that additional people were needed to continue to operate the publishing program; therefore, a request was made to hire a part-time staff member. Unfortunately, the funding request for the position was denied, and it was clear that it was not likely to be funded in the future. Since the number of staff could not be increased, it was decided that the amount of work the publishing program had taken on needed to decrease.

It is never easy to decide to reduce the level of service offered to anyone or to decide to stop providing a service entirely. By nature, librarians are service-oriented. However, in some instances, it is necessary to make hard choices in order to move forward and achieve new goals. At Pacific, it was determined that we would decrease the number of journals published in order to concentrate on book publishing via Pacific University Press. This decision was made because there are currently fewer opportunities for scholars to publish open 
access monographs than open access articles. It is the hope that producing more open access monographs will have greater impact on the scholarly publishing landscape over time than our journal publishing was having. This focus on book publishing also has other benefits. In some ways, book publishing is simpler than journal publishing in that it has a definitive starting and ending point, as opposed being an indefinite, long-term commitment. It is also easier to schedule time to work on a book around other projects as opposed to journal publishing, which has much more varied timelines that are contingent upon many more people. Depending on the journal editor or editors, receiving materials from them according to the agreed-upon schedule can vary, and, as editors change, reliability often shifts. Editors are further reliant on authors to turn in their articles and respond to peer reviews in a timely manner. With books, there are generally fewer people involved, as well as fewer deadlines. Even if the author is late turning in the manuscript, it is less of an obstacle because publication dates for books are usually more abstract at this stage than journal issue publication dates. Therefore, although books are longer than an average journal issue, the parts that are out of a publisher's control are less of an obstacle.

In order to decrease the amount of time spent on journal publishing, we combined two undergraduate journals into one, and the editors were provided with a template for their articles so that they could complete their own typesetting. Additionally, we rehomed a journal that we hosted to a library at a different institution and ceased publishing another journal altogether. This brought the total number of journals from seven to three and decreased the amount of typesetting significantly. In addition, these changes happened in conjunction with a migration of our institutional repository from Digital Commons, which had previously hosted all but one of our journals. When our institutional repository migrated away from bepress, our journals were also migrated to Ubiquity Press. Although Digital Commons does not charge its users a fee per journal site, after the migration, we would be charged per journal; therefore, reducing the total number of journals published has also saved a significant amount of money. Also, considering that the focus of publishing in the future will be on books, the cost for journal publishing will not grow, as additional journals will not be added.

While the process of making these choices internally was difficult, communicating it to stakeholders, such as journal editors, was harder. It is impossible to know what to expect when opening up a conversation like this, but overall, ours went smoothly. The editor of the subject-specific undergraduate journal whose publications would become special issues of the general undergraduate journal had no issues. The stakeholders of OLA Quarterly, an official publication of the Oregon Library Association, assisted in finding a new home at Oregon State University. We collaborated to migrate the content to their journal platform, which did not require an overwhelming amount of time or effort on our part. The journal was also being migrated from bepress to Oregon State's instance of Open Journal Systems, which added some 
complexity. The journal that Pacific ceased publishing was a bit trickier, but the editor successfully found a new home with our support. Although it was stressful to create new boundaries for our services and even more stressful to communicate them, it allowed Pacific to reclaim its trajectory as a library publisher and to move forward in a purposeful way toward new goals. In addition, the journals themselves were also better set up for success as a result. The undergraduate journal had recently received grant funding and had strong editorial support, which benefited the journal merging with it. OLA Quarterly is now being supported by a larger, state-funded institution and can benefit from that stability. The journal that we ceased publishing has found a home with staff members who provide many services while still publishing the journal open access.

In addition, right as these changes to our publishing program and migration to new platforms was being completed, Johanna Meetz, the former scholarly communication and publishing services librarian, accepted a position at the Ohio State University. Since job descriptions are often revised when people leave, this meant that there was another opportunity to make additional changes. It was decided that collection management services staff would take over the technical management of the institutional repository, whereas the future scholarly communication and publishing services librarian would only be responsible for the outreach efforts around the IR. The future scholarly communication and publishing services librarian would continue to oversee the publishing program at Pacific. ${ }^{2}$

\section{The University of South Florida}

The University of South Florida Libraries began publishing open access journals in 2008 . Along with electronic theses and dissertations, open access journals were among the first items in the new institutional repository and signified the first push to support open access across campus. Over the years, the number of journals supported by the library increased to over 20 . Some journals were brand new, and some were converted from society publishers into open access. The open access publishing program became one of the premier examples of the University of South Florida Libraries support for open access.

Staffing levels attempted to match the increased numbers of open access journals supported by the library. By 2020, there was a librarian, two administrative employees, and one staff member working, in some capacity, on open access journals. One administrative employee worked the majority of their time with open access journal editors and the institutional repository vendor bepress. This involved assisting with many aspects of the publication process for each issue

\footnotetext{
${ }^{2}$ It is worth noting that, although Pacific University has now hired an additional faculty librarian, as of 2021, a scholarly communication and publishing services librarian position has not been opened.
} 
published for a dozen of the journals. While helping editors with questions, technical issues, workflow reminders, etc., the open access journal publishing program had scaled to meet the needs of journal editors, which are reflected in their respective Memorandum of Understanding (MOU).

Over time, and with different levels of library staffing, the individual MOU's include different levels of service. With some journals, the library would support complicated layouts and lengthy layout revisions. With others, we would only register digital object identifiers (DOIs) with CrossRef. The spectrum of service was wide.

Each journal has a different publication cycle. There are journals that publish incrementally and others that publish by completing an issue. A few journals required in-depth layout by the library. Some layouts required a significant amount of staff time, especially when editors and authors asked for substantial edits to the laid-out articles. Layout services were not offered when negotiating with potential editors of new journals looking to be added to the repository.

The library had reached a limit in the number of journals it was capable of supporting with its full range of services. Scaling up the program would require offering journals a smaller support package or increasing staff levels. The open access publishing unit saw the ramifications of offering specialized services to each journal. Training new staff on the differences between journals was difficult. Predicting time investments was difficult; journals did not always follow a strict publishing schedule, and there was inconsistency in layout requirements. As a result, new requests for journal hosting were met with increased scrutiny to ensure that the editors could adequately support the new journal. The service suite that the library had offered to some editors, as well as an inability to hire more faculty or staff support, was limiting the ability of the program to expand.

When COVID-19 emerged in 2020, the University of South Florida Libraries faced a reduced budget. Some library resources were not renewed, and collections were cut, resulting in a loss of instant access. The University of South Florida Libraries opted to reduce support for some programs and move staff into new areas in the library. With anticipated usage increases in InterLibrary Loan and additional support in technical services to handle the influx of analytical analysis to properly cancel titles, personnel were moved into these departments. As a result, two staff members would be removed from the open access journals program by the end of 2020 and relocated to different departments in the library.

The publishing unit began preparations in scaling down services to our over 20 journals to prepare for the transition. As mentioned earlier, the services offered to our journals varied. Some received numerous services such as article layouts and even cover design, whereas, for others, the 
library simply registered DOIs. The open access publishing unit created a master list of all the journals we supported as well as the library services offered. The open access publishing unit determined the services that we could continue to offer from 2021 onward. The services could not be a large time commitment, and they needed to be streamlined.

There is a balancing act when considering which services will be stopped and which ones will be kept. In the case of the University of South Florida Libraries, where we were looking for ways to dramatically cut staff time, services that were only offered to a small subset of journals and took up a lot of staff time were easy to choose for elimination. Two of the biggest examples of these were article layout services and designing issue covers. Services that are automated or partially automated were easily chosen to be kept.

One of the most valued, but easily implemented, services we offer to all the journals is DOI registration. This process was made easier by utilizing a bash script to create an XML file for CrossRef deposit. Similarly, our unit has a script to generate DOAJ XML for deposit. Any of our journals that are included in DOAJ have their metadata uploaded quickly.

Whereas a lot of the technical aspects of the journals were handed back to the editors, such as publishing issues in the bepress system, which the library often did previously, the consultations the library offered about open access and open access publishing needed to remain. The open access publishing unit will continue to speak with editors and answer questions about open access best practices and other editorial questions when they need assistance.

It was decided that we would offer the same service to all the journals; we would no longer offer layouts and other time intensive services to select journals. This would help with some of the issues regarding the time to train staff employees or unpredictability of the journals. In order to do this, an email from the Associate Dean alerted the editors of the budget situation, the movement of staff, and how this would affect their journal specifically. The open access publishing unit then provided an addendum to each journal's original MOU that laid out the explicit responsibilities for the library and the journal. The unit also provided the journal editors with all of the internal library files for their journal, including any InDesign templates that we had for layouts, workflow documentation, and other design elements such as logos. The open access publishing unit emphasized to all of the journal editors that consultations and trainings were available to explain how the publishing unit had previously performed these services.

The entire process of discontinuing services was completed in 3 months at the end of 2020 . All of the staff in the open access publishing unit assisted with the creation of MOU addendums, emailing stakeholders, and setting up meetings to discuss the transition and provide training. The time commitment during those 3 months was significant, but it allowed staff to properly 
work with editors on establishing a usable workflow for the future. There was an emphasis on communicating clearly and consistently with all of the stakeholders. The reminder emails were sent regularly. As a result, some of the editors signed up for training on the services they would now have to perform, whereas other editors replied back lamenting the sad fact that it was necessary for the library to discontinue these services. At the end of the process, the open access publishing unit was able to assist many of the journal editors with the tools they required to continue their journal production.

\section{LESSONS LEARNED}

Although our institutions and publishing programs have been very different, many of the lessons learned have been similar. Both programs grew beyond the capacity of current staff over time, have struggled with sustainability and scalability of services, and have faced additional challenges due to COVID-19. In the end, although the University of South Florida's program published more journals and had additional dedicated staff time, they faced the same challenges even before the redistribution of staff to other departments due to COVID-19. No matter the size of the institution or the publishing program, no library is immune to the limits of its resources.

The process of making changes to each of our services made several things clear. First, it is vital to recognize that no library publishing program can grow indefinitely without the ability to hire additional faculty or staff. In some ways this seems obvious, but, in reality, it is not always acknowledged. More often than not, the library publishing community is focused on continual growth and, in fact, is expected to constantly expand in order to increase its capacity to change the landscape of scholarly publishing. Although this is certainly laudable, it is not practical; moreover, growth is only one measure of success. In general, there seems to be a lack of understanding of just how much work publishing is, especially for library publishers that offer a full-service model that includes copyediting and/or typesetting. This extends to anyone who does not do this work, including library staff, administrators, authors, and journal editors. Even without those time-consuming and more technical services, training and working with editors, registering DOIs, preserving content, and creating and maintaining a journal website-among other tasks_all take time, effort, and management. When the services the publishing programs provide to each journal vary, it also creates additional overhead to effectively track and administer the workflows associated with each publication.

Second, it is important to think about the level of service that can be offered and sustained as a publishing program grows in accordance with its goals. For example, if a program's goal is to publish as many journals as possible, it is wise to be wary of offering more time-consuming services such as copyediting or typesetting. Also, standardizing services and workflows as 
much as possible from the start in order to create and maintain efficiency is vital and will allow for scalable growth into the future. Thinking realistically about projects the program may be offered that cannot be sustained by current faculty or staff is imperative, as opportunities to hire additional people are not a given.

Last, creating a business plan or a set of documents that outline the program's mission, vision, and goals is crucial in order to begin and grow sustainably (McCready and Molls, 2018). Time should be set aside to review these documents on an annual or biannual basis to make sure that the stated goals still reflect realistic and aspirational targets for the program. Moreover, these documents, or internal documents based on these, should be referenced and used as the basis for making decisions about taking on new projects, offering new services, or making any changes in general. It is important not to get lost in the trenches of the labor of publishing and to take the time to actively curate a publishing program in an agreed-upon direction. These documents and the practice of using and maintaining them will help ground a publishing program and set it up to be successful over time.

\section{NEXT STEPS}

\section{Pacific University}

Unfortunately, the COVID-19 pandemic and financial concerns resulting from it impeded the hiring of a new scholarly communication and publishing services librarian at Pacific. Since then, the Libraries' focus has shifted to address other, more pressing needs on campus, and a search is currently active for a health sciences student success librarian. In addition, the difficult decision was made to part ways with another of Pacific's journals, The Journal of Librarianship and Scholarly Communication, which has found a new home with Iowa State's publishing program and hopes to achieve its more ambitious goals there. The current publishing program at Pacific is sustained by freelancers and the Dean of Libraries. Despite the complications caused by COVID-19, Pacific University Press published its most recent book in 2020. There is also a new initiative within the Libraries to encourage the use of open educational resources on campus, which connects nicely to the program's new focus on book publishing.

\section{The University of South Florida}

As mentioned earlier, the University of South Florida will continue offering select services to journals, including registering DOIs to CrossRef, registering metadata to DOAJ, and providing open access consultation support. The University of South Florida Libraries plans to periodically check in with journal editors to assess how the new roles are affecting the journals. It is the hope of the University of South Florida Libraries that the lowering of services offered has not negatively affected any journals to the point that they have to consider ceasing publication. 
Additionally, with a new and streamlined approach to open access journal management set forth in this new process, it is hoped that, in the future, the library will be able to add additional journals within this service paradigm.

\section{CONCLUSION}

In many ways, COVID-19 has shone a spotlight on the importance of scholarly communication and publishing work; ensuring that researchers worldwide and the public have access to scholarly articles and data is vital. However, budget issues that were already present at most - if not all—colleges and universities are, and will continue to be, challenging. Many of the difficulties already faced by library publishing programs, such as sustainability and scalability, have been exacerbated by the effects of COVID-19. Difficult choices about priorities are likely to continue, and publishing programs will be no exception. Still, at its heart, library publishing is experimental and innovative, and its practitioners are motivated and dedicated. Although we will need to adapt and shift our practices as we grow beyond our limits, this type of work and the flexibility it requires is not new to librarianship.

\section{REFERENCES}

Hawkins, K., Lippincott, S., \& McCormick, M. (2014, June 23). What are libraries doing as publishers? [Conference presentation]. American Association of University Presses 2014, New Orleans, Louisiana, United States. https://educopia.org/what-are-libraries-doing-as-publishers/

Library Publishing Coalition. (2021a, April 24). About us. https://librarypublishing.org/about/

Library Publishing Coalition. (2021b, April 24). Library publishing directory. https://librarypublishing.org/ lp-directory/

Lippincott, S. K. (2016, July 5). The Library Publishing Coalition: organizing libraries to enhance scholarly publishing. Insights, 29(2), 186-191. http://doi.org/10.1629/uksg.296

Lippincott, S. K. (2017). Library as publisher: New models of scholarly communication for a new era. Against the Grain (Media), LLC. https://doi.org/10.3998/mpub.9944345

McCready, K., \& Molls, E. (2018, October 23). Developing a business plan for a library publishing program. Publications, 6(4), 42. https://doi.org/10.3390/publications6040042

Okerson, A., \& Holzman, A. (2015, July). The once and future publishing library. Council on Library and Information Resources. https://www.clir.org/wp-content/uploads/sites/6/pub166.pdf

Pacific University Libraries. (2021, April 24). About Pacific University Press. https://www.lib.pacificu.edu/ create/pup/pup-about/ 